\title{
Cortex Effect on Vacuum Drying Process of Porous Medium
}

\author{
Zhijun Zhang, ${ }^{1}$ Shiwei Zhang, ${ }^{1}$ Tianyi Su, ${ }^{1}$ and Shuangshuang Zhao ${ }^{2}$ \\ ${ }^{1}$ School of Mechanical Engineering and Automation, Northeastern University, Shenyang 110004, China \\ ${ }^{2}$ Shenyang Aircraft Design and Research Institute, Shenyang 110035, China
}

Correspondence should be addressed to Zhijun Zhang; zhjzhang@mail.neu.edu.cn

Received 25 February 2013; Accepted 5 April 2013

Academic Editor: Jun Liu

Copyright (C) 2013 Zhijun Zhang et al. This is an open access article distributed under the Creative Commons Attribution License, which permits unrestricted use, distribution, and reproduction in any medium, provided the original work is properly cited.

\begin{abstract}
Corns, fruits, and vegetables are usually used as porous medium in drying process. But in fact, it must be considered as the cortex effect on mass transfer because the mass transfer of cortex is very difficult than inner medium. Based on the theory of heat and mass transfer, a coupled model for the porous medium vacuum drying process with cortex effect is constructed. The model is implemented and solved using COMSOL software. The water evaporation rate is determined using a nonequilibrium method with the rate constant parameter $K_{r}$ that has been studied. The effects of different vapor pressures $(1000,5000$, and $9000 \mathrm{~Pa})$, initial moisture contents $(0.3,0.4$, and 0.5 water saturation), drying temperatures $(323,333$, and $343 \mathrm{~K})$, and intrinsic permeability for cortex part $\left(10^{-13}, 10^{-14}, 10^{-15} \mathrm{~m}^{2}\right)$ on vacuum drying process were studied. The results facilitate a better understanding of the porous medium vacuum drying process that nearer to the reality.
\end{abstract}

\section{Introduction}

Scientists and engineers in China are currently studying vacuum drying equipment that could be used in corn drying $[1-3]$. However, the corn vacuum drying theory remains unclear. Hypothesized that corn is a porous medium, the vacuum drying of corn is a complicated heat and mass transfer process that has been the subject of intensive research [4-7]. All vacuum drying models have to address the water phase change during numerical solving. In one method, the vapor pressure is equal to its equilibrium value [8-11]. Another method is nonequilibrium method [12-16]. As the porous medium, the heat and mass transfer in vacuum drying process has been studied by nonequilibrium method [17]. The water evaporation rate is determined using a nonequilibrium method with the rate constant parameter $K_{r} . K_{r}$ values of 1,10 , 1000 , and 10000 are simulated. The effects of different vapor pressures (1000, 5000, and $9000 \mathrm{~Pa})$, initial moisture contents $(0.4,0.5$, and 0.6 water saturation), drying temperatures $(323,333$, and $343 \mathrm{~K})$, and intrinsic permeability $\left(10^{-13}, 10^{-14}\right.$, $10^{-15} \mathrm{~m}^{2}$ ) are studied. It was observed that the temperature increased quickly at the start of drying and then lowered gradually. As the drying process continued, the temperature increased slowly. In the absence of free water, temperature increased rapidly. As the drying process concluded, the temperature remained unchanged. The water evaporation rate could not be obtained during the porous medium vacuum drying process. The rate constant parameter is essential to the nonequilibrium method. When $K_{r} \geq 1000$, the simulation of the drying process was not evidently affected. Vapor pressure and heat transfer affected the transfer of mass. A similar effect was found in the initial moisture and the heat temperature. Intrinsic permeability had a greater effect on the drying process. In the study above, it is as the uniform porous medium. But in fact, it must be considered as the cortex effect on mass transfer because the mass transfer of cortex is more difficult than inner medium. The study of about cortex effect is very few.

In this paper, heat and mass transfer of porous medium with cortex in the vacuum drying process is implemented by using a nonequilibrium method. The effects of vapor pressure, initial moisture, heat temperature, and cortex intrinsic permeability on the drying process were then examined.

\section{Physical Model}

A physical one-dimensional (1D) model that explains the drying process is shown in Figure 1. The heat and mass 


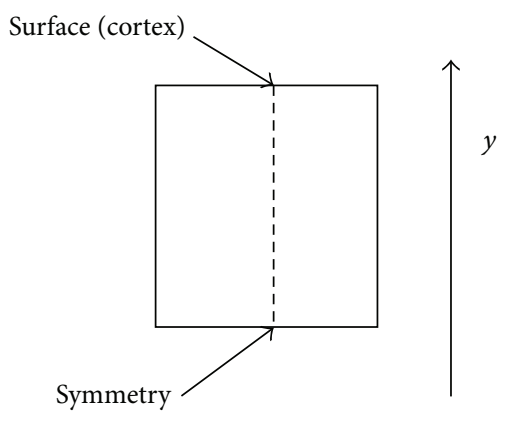

FIgURE 1: 1D model of porous medium with cortex.

transfer is considered only in the $y$ direction. Because consider the cortex effect. The heat and mass transfer is through the surface of medium that is the cortex position. The total height of the porous medium is $1.05 \mathrm{~cm}$, and the cortex height is $0.05 \mathrm{~cm}$.

\section{Mathematical Model}

The porous medium consists of a continuous rigid solid phase, an incompressible liquid phase (free water), and a continuous gas phase that is assumed to be a perfect mixture of vapor and dry air, considered as ideal gases. For a mathematical description of the transport phenomenon in a porous medium, we adopt a continuum approach, wherein macroscopic partial differential equations are achieved through the volume averaging of the microscopic conservation laws. The value of any physical quantity at a point in space is given by its average value on the averaging volume centered at this point.

The moisture movement of the inner porous medium is liquid water and vapor movement; that is, the liquid water could become vapor, and the vapor and liquid water are moved by the pressure gradient. The heat and mass transfer theory could be found in everywhere [8].

The compressibility effects of the liquid phase are negligible, and the phase is homogeneous:

$$
\bar{\rho}_{l}=\text { constant }
$$

The solid phase is rigid and homogeneous:

$$
\bar{\rho}_{s}=\text { constant. }
$$

The gaseous phase is considered an ideal gas. This phase ensures that

$$
\begin{gathered}
\bar{\rho}_{a}=\frac{m_{a} P_{a}}{R \bar{T}}, \\
\bar{\rho}_{v}=\frac{m_{v} \bar{P}_{v}}{R \bar{T}}, \\
\bar{P}_{g}=\bar{P}_{a}+\bar{P}_{v}, \\
\bar{\rho}_{g}=\bar{\rho}_{a}+\bar{\rho}_{v} .
\end{gathered}
$$

The assumption of the local thermal equilibrium between the solid, gas, and liquid phases involves

$$
\bar{T}_{s}=\bar{T}_{g}=\bar{T}_{l}=\bar{T}
$$

Mass conservation equations are written for each component in each phase. Given that the solid phase is rigid, the following is given:

$$
\frac{\partial \bar{\rho}_{s}}{\partial t}=0
$$

The averaged mass conservation of the dry air yields

$$
\frac{\partial\left(\varepsilon \cdot S_{g} \bar{\rho}_{a}\right)}{\partial t}+\nabla \cdot\left(\bar{\rho}_{a} \bar{V}_{a}\right)=0 .
$$

For vapor,

$$
\frac{\partial\left(\varepsilon \cdot S_{g} \bar{\rho}_{v}\right)}{\partial t}+\nabla \cdot\left(\bar{\rho}_{v} \bar{V}_{v}\right)=\dot{I} .
$$

For free water,

$$
\frac{\partial\left(\varepsilon \cdot S_{w} \bar{\rho}_{l}\right)}{\partial t}+\nabla \cdot\left(\bar{\rho}_{l} \bar{V}_{l}\right)=-\dot{I} .
$$

For water, the general equation of mass conservation is obtained from the sum of the conservation equations of vapor $(v)$ and free water $(l)$. The general equation is written as follows:

$$
\begin{gathered}
\frac{\partial W}{\partial t}+\nabla \cdot\left\{\frac{1}{\bar{\rho}_{s}}\left(\bar{\rho}_{l} \bar{V}_{l}+\bar{\rho}_{v} \bar{V}_{v}\right)\right\}=0, \\
W=\frac{\varepsilon \cdot S_{w} \bar{\rho}_{l}+\varepsilon \cdot S_{g} \bar{\rho}_{v}}{(1-\varepsilon) \bar{\rho}_{s}} .
\end{gathered}
$$

For the Darcy flow of vapor,

$$
\bar{\rho}_{v} \bar{V}_{v}=\bar{\rho}_{v} \bar{V}_{g}-\bar{\rho}_{g} D_{\mathrm{eff}} \cdot \nabla \bar{\omega} .
$$

For the Darcy flow of air,

$$
\bar{\rho}_{a} \bar{V}_{a}=\bar{\rho}_{a} \bar{V}_{g}-\bar{\rho}_{g} D_{\text {eff }} \cdot \nabla \bar{\omega}
$$

where the gas and free water velocity is given by

$$
\begin{gathered}
\bar{V}_{g}=\frac{k \cdot k_{r g}}{\mu_{g}} \cdot\left(\nabla \bar{P}_{g}-\rho_{g} \vec{g}\right), \\
\bar{V}_{l}=\frac{k \cdot k_{r l}}{\mu_{l}} \cdot\left(\nabla \bar{P}_{l}-\rho_{l} \vec{g}\right) .
\end{gathered}
$$

The effective diffusion coefficient [8] is given by

$$
D_{\text {eff }}=D \underline{\underline{B}} \text {. }
$$

The vapor fraction in mixed gas is given by

$$
\bar{\omega}=\frac{\rho_{v}}{\rho_{g}} .
$$


TABLE 1: Parameters used in the simulation process.

\begin{tabular}{lccc}
\hline Parameter & Symbol & Value & \\
\hline Rate constant parameter & $K_{r}$ & 1000 & Unit \\
Intrinsic permeability of inner medium & $k_{\text {in }}$ & $10^{-13}$ & $\mathrm{~s}^{-1}$ \\
Intrinsic permeability of cortex & $k_{\text {cor }}$ & $10^{-13}, 10^{-14}, 10^{-15}$ & $\mathrm{~m}^{2}$ \\
Initial water saturation & $S_{l 0}$ & $0.5,0.4,0.3$ & $\mathrm{~m}^{2}$ \\
Vapor pressure of vacuum drying chamber & $P_{v b}$ & $1000,5000,9000$ & $323,333,343$ \\
Heat temperature & $T_{h}$ & 0.615 & $\mathrm{~K}$ \\
Porosity & $\varepsilon$ & 476 & $\mathrm{~kg} \mathrm{~m}^{-3}$ \\
Solid density & $\rho_{s}$ & 0.001 & $\mathrm{~Pa}$ \\
Air pressure of vacuum drying chamber & $P_{a b}$ & & \\
\hline
\end{tabular}

The pressure moving the free water is given by

$$
\bar{P}_{l}=\bar{P}_{g}-\bar{P}_{c} \text {. }
$$

For capillary pressure,

$$
\bar{P}_{c}=56.75 \times 10^{3}\left(1-S_{l}\right) \exp \left(\frac{1.062}{S_{l}}\right) .
$$

The saturation of free water and gas is

$$
S_{g}+S_{l}=1 \text {. }
$$

Free water relative permeability is given by

$$
k_{r l}= \begin{cases}\left(\frac{S_{l}-S_{c r}}{1-S_{c r}}\right)^{3} & S_{w}>S_{c r} \\ 0 & S_{w} \leq S_{c r}\end{cases}
$$

Gas relative permeability is given by

$$
k_{r g}=S_{g} .
$$

The water phase change rate is expressed as

$$
\dot{I}=K_{r} \frac{m_{v}\left(a_{\omega} P_{\mathrm{sat}}-P_{v}\right) S_{g} \varepsilon}{R T} .
$$

Water saturation vapor pressure is given by

$$
P_{\text {sat }}=\frac{101325}{760} \times 10^{(8.07131-(1730.63 /(233.426+(T-273))))} \text {. }
$$

By considering the hypothesis of the local thermal equilibrium, the energy conservation is reduced to a unique equation:

$$
\begin{aligned}
& \frac{\partial \bar{\rho} \bar{h}}{\partial t}+\nabla \cdot\left\{\left(\bar{\rho}_{a} \bar{V}_{a} \bar{h}_{a}+\bar{\rho}_{v} \bar{V}_{v} \bar{h}_{v}\right.\right. \\
& \left.\left.+\bar{\rho}_{l} \bar{V}_{l} \bar{h}_{l}-\lambda_{e} \cdot \nabla \bar{T}-\Delta H \cdot \dot{I}\right)\right\}=0, \\
& \lambda_{e}=(1-\varepsilon) \lambda_{s}+\varepsilon\left(S_{l}+S_{g}\left(\omega \lambda_{v}+(1-\omega) \lambda_{a}\right)\right), \\
& \bar{\rho} \bar{h}=\bar{\rho}_{s} \bar{h}_{s}+\varepsilon \cdot S_{g} \bar{\rho}_{a} \bar{h}_{a}+\varepsilon \cdot S_{g} \bar{\rho}_{v} \bar{h}_{v}+\varepsilon \cdot S_{l} \bar{\rho}_{l} \bar{h}_{l} .
\end{aligned}
$$

\section{Boundary Condition and Parameters}

The air pressure on the external surface of the porous medium is fixed, and the boundary condition for air is given by

$$
P_{a}=P_{a v}
$$

The boundary condition for vapor at the surface of the porous medium is given by

$$
P_{v}=P_{v b}
$$

To simulate the vapor pressure of the vacuum drying chamber effect on the drying process, four different vapor pressure boundary values are used.

The boundary condition for free water at the top of the porous medium is

$$
n \cdot\left(-D \nabla S_{w}\right)=0 \text {. }
$$

The boundary condition at the surface of the porous medium is

$$
T=T_{h}
$$

Three different $T_{h}$ values are used in the simulation.

The initial moisture of the porous medium is represented by the liquid water saturation; different initial water saturation values are used. To compare the effects, drying base moisture content (d.b.) was also used, as shown in (9). The water phase change rate is used as 1000 that has been studied before [17]. Intrinsic permeability of inner medium is $10^{-13} \mathrm{~m}^{2}$. Intrinsic permeability of cortex is $10^{-14}, 10^{-15} \mathrm{~m}^{2}$. In order to compare the results, the intrinsic permeability of cortex $10^{-13}$, that is no cortex effect is simulated. In order to easily converge in, the parameter changer is used a smooth method. The modeling parameters are shown in Table 1.

\section{Numerical Solution}

COMSOL Multiphysics 3.5a was used to solve the set of equations. COMSOL is an advanced software used for modeling and simulating any physical process described by partial derivative equations. The set of equations introduced above was solved using the relative initial and boundary conditions of each. COMSOL offers three possibilities for writing the 
equations: (1) using a template (the Fick law and the Fourier law), (2) using the coefficient form (for mildly nonlinear problems), and (3) using the general form (for most nonlinear problems). Differential equations in the coefficient form were written using an unsymmetric-pattern multifrontal method. We used a direct solver for sparse matrices (UMFPACK), which involves significantly more complicated algorithms than solvers used for dense matrices. The main complication is the need to handle the fill-in in factors $L$ and $U$ efficiently.

A two-dimensional (2D) grid was used to solve the equations using COMSOL Multiphysics 3.5a. Given the symmetry condition setting at the left and the right sides, The $2 \mathrm{D}$ is applied to the the $1 \mathrm{D}$ model shown in Figure 1. The mesh consists of $2 \times 200$ elements (2D), and time stepping is 1 (from $0 \mathrm{~s}$ to $100 \mathrm{~s}$ of solution), 5 (from $100 \mathrm{~s}$ to $200 \mathrm{~s}$ of solution), 20 (from $200 \mathrm{~s}$ to $1000 \mathrm{~s}$ of solution), 30 (from $1000 \mathrm{~s}$ to $2000 \mathrm{~s}$ of solution), 40 (from $2000 \mathrm{~s}$ to $4000 \mathrm{~s}$ of solution), 50 (from $4000 \mathrm{~s}$ to $20000 \mathrm{~s}$ of solution), and 100 (from $20000 \mathrm{~s}$ to $50000 \mathrm{~s}$ of solution). Several grid sensitivity tests were conducted to determine the sufficiency of the mesh scheme and to ensure that the results are grid independent. The maximum element size was established as $1 e^{-4}$. A backward differentiation formula was used to solve time-dependent variables. Relative tolerance was set to $1 e^{-3}$, whereas absolute tolerance was set to $1 e^{-4}$. The simulations were performed using a Tongfang PC with Intel Core 2 Duo processor with $3.0 \mathrm{GHz}$ processing speed, and $4096 \mathrm{MB}$ of RAM running Windows 7.

\section{Results and Discussion}

6.1. Effect of Boundary Condition. In the study before [17], the heat and mass transfer direction is the same. That is, the heat boundary is on the bottom of the medium. The heat transfer is from the bottom to top. The mass transfer boundary is on the top of bottom. The mass transfer is from the bottom to top by the pressure driving. But in this study, the cortex is considered. And the heat transfer and mass transfer are on the reversed direction as Figure 1. The heat and mass transfer with dryer is on the surface of the medium. The both condition was simulated to be compared as Figure 2. The simulation parameters are $S_{l 0}=0.5, K_{r}=1000, T_{h}=323 \mathrm{~K}, P_{v b}=$ $1000 \mathrm{~Pa}, k_{\mathrm{in}}=10^{-13} \mathrm{~m}^{2}$, and no cortex. The moisture curve is just little different. The drying rate is little larger at the drying initial stage for same direction heat and mass transfer, and then it is little lower. The other condition is just reversed. The drying rate is little lower at the initial stage for reversed direction heat and mass transfer, and then it is little larger. The drying time for both is 6 hours.

6.2. Effect of Cortex Resistance. Intrinsic permeability of porous medium is an inherent property and cannot be changed, and measuring it is difficult. Intrinsic permeability has a greater effect because the transfer of free water and vapor is affected by (13). Usually, the cortex intrinsic permeability is less than inner medium. Figure 3 is the moisture curves of no cortex $\left(k_{\text {in }}\right.$ and $k_{\text {cor }}=10^{-13}, 10^{-14}$, and $10^{-15} \mathrm{~m}^{2}$, resp.), with cortex $\left(k_{\text {in }}=10^{-13}\right.$ and $k_{\text {cor }}=10^{-14}$ and $10^{-15} \mathrm{~m}^{2}$ resp.). The other simulation parameters are $S_{l 0}=0.5, K_{r}=$

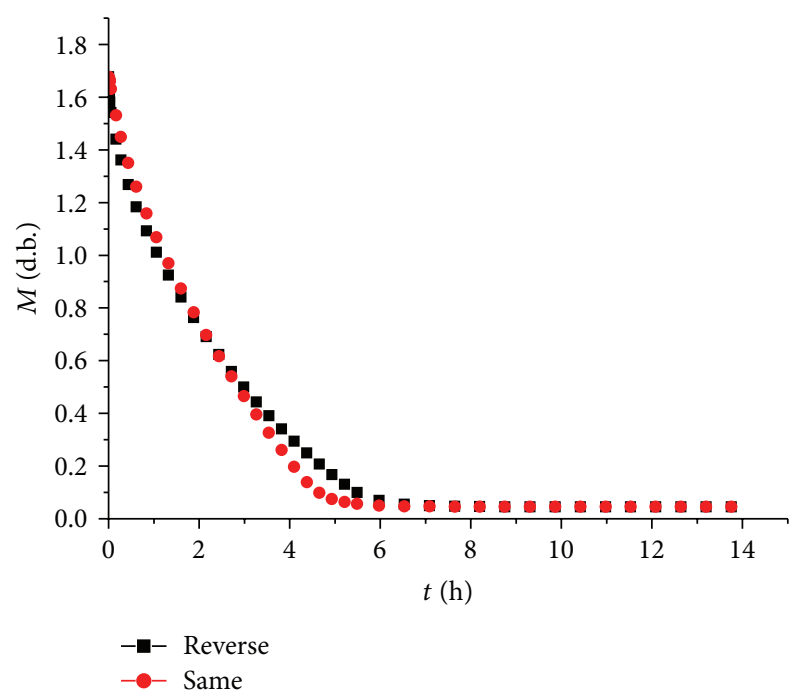

FIGURE 2: The effect of boundary condition, heat, and mass transfer is same and is reverse direction.

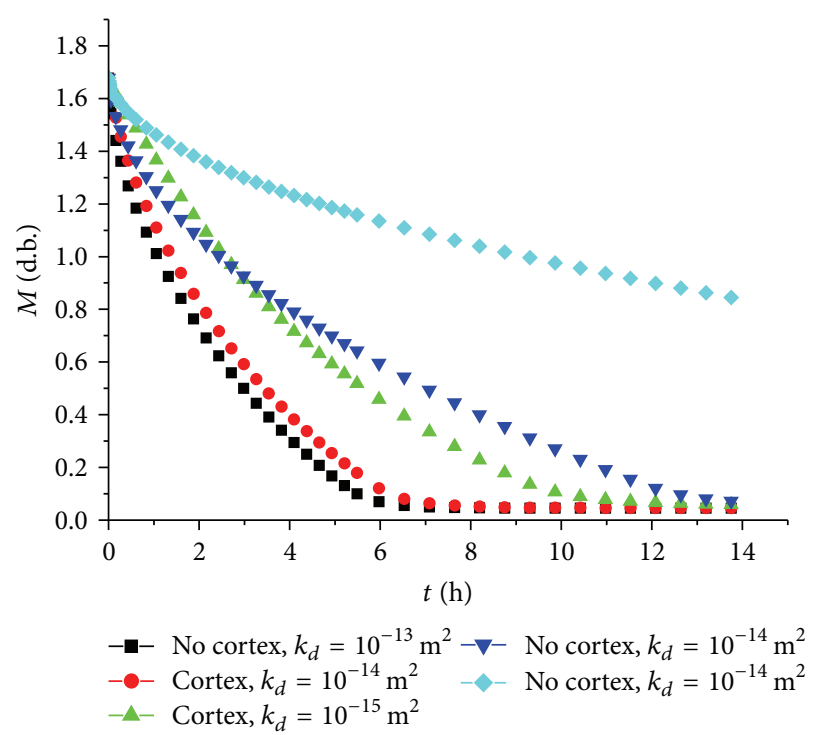

FIgURE 3: Moisture curves of no cortex $\left(k_{\text {in }}=10^{-13}, k_{\text {cor }}=10^{-13}\right.$, $10^{-14}$, and $\left.10^{-15} \mathrm{~m}^{2}\right),\left(k_{\text {cor }}=10^{-14}, 10^{-15}, k_{\mathrm{in}}=10^{-13} \mathrm{~m}^{2}\right)$.

$1000, T_{h}=323 \mathrm{~K}$, and $P_{v b}=1000 \mathrm{~Pa}$. The drying time became evidently longer as the intrinsic permeability was reduced because the moisture movement velocity was lowered at the same pressure gradient. The different is not so obviously as the $k_{\text {cor }}=10^{-14} \mathrm{~m}^{2}$, that is lower 10 -fold than inner medium. But when $k_{\text {cor }}=10^{-15} \mathrm{~m}^{2}$, the drying time is increased to 2 -fold nearly. In order to compare, the no cortex, $k_{\text {cor }}=10^{-14} \mathrm{~m}^{2}$, and $10^{-15} \mathrm{~m}^{2}$ was shown. Because the numerical calculation is not convergence, the cortex $k_{\text {cor }}=10^{-16} \mathrm{~m}^{2}, k_{\mathrm{in}}=10^{-13} \mathrm{~m}^{2}$ result not gotten. The reason is that the material parameter changer is too big.

6.3. Effect of Vapor Pressure in Vacuum Drying Chamber. The pressure of a vacuum drying chamber, especially vapor 


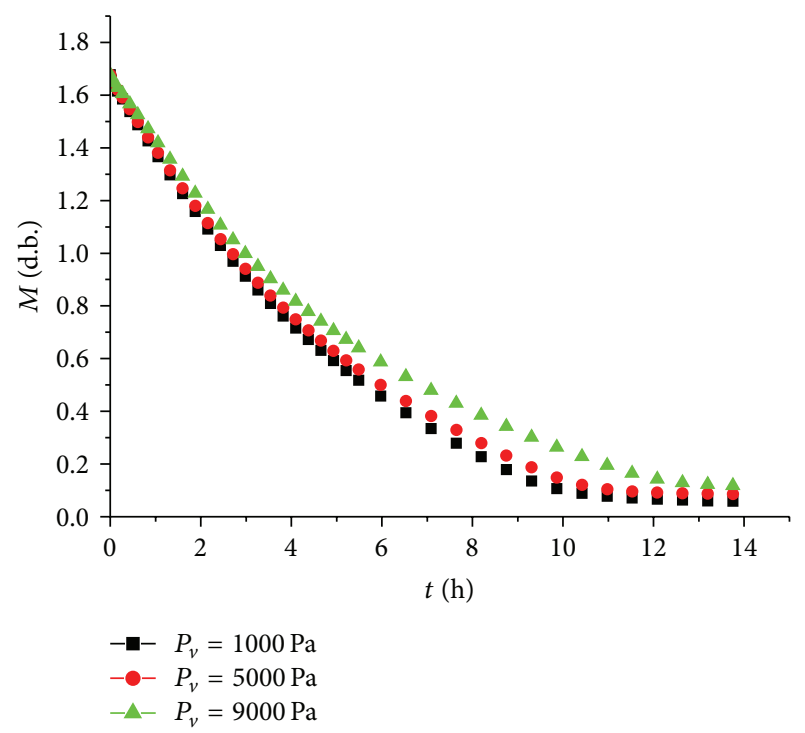

Figure 4: Moisture curves of different $P_{v b}=1000,5000,9000 \mathrm{~Pa}$, $k_{\text {cor }}=10^{-15} \mathrm{~m}^{2}, k_{\text {in }}=10^{-13} \mathrm{~m}^{2}$.



Figure 5: Moisture curves of different $P_{v b}=1000,5000,9000 \mathrm{~Pa}$, $k_{\text {cor }}=10^{-14} \mathrm{~m}^{2}, k_{\text {in }}=10^{-13} \mathrm{~m}^{2}$.

pressure, plays an important role in the vacuum drying process and is also linked to the drying cost. The moisture curves of $P_{v b}=1000,5000$, and $9000 \mathrm{~Pa}$ are shown in Figures 4,5 , and 6 with different cortex intrinsic permeability. The other simulation parameters are $S_{l 0}=0.5, K_{r}=1000$, and $T_{h}=323 \mathrm{~K}$. The vapor pressure has a greater effect on the drying process; a lower vapor pressure results in greater pressure degradation. The movements of free water and vapor as well as the free water evaporation rate are quicker, as given by (13) and (21), respectively. But the pressure effect is lower by the cortex intrinsic permeability reduced.

6.4. Effect of Initial Moisture Content. The effect of initial moisture content on the moisture curve is shown in Figures 7,

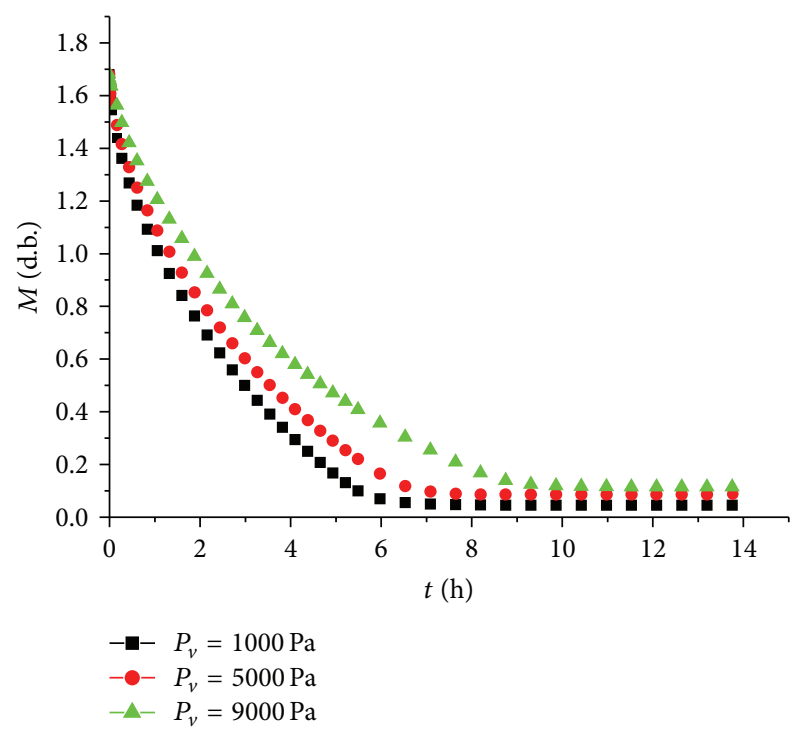

Figure 6: Moisture curves of different $P_{v b}=1000,5000,9000 \mathrm{~Pa}$, no cortex, $k_{\mathrm{in}}=10^{-13} \mathrm{~m}^{2}$.

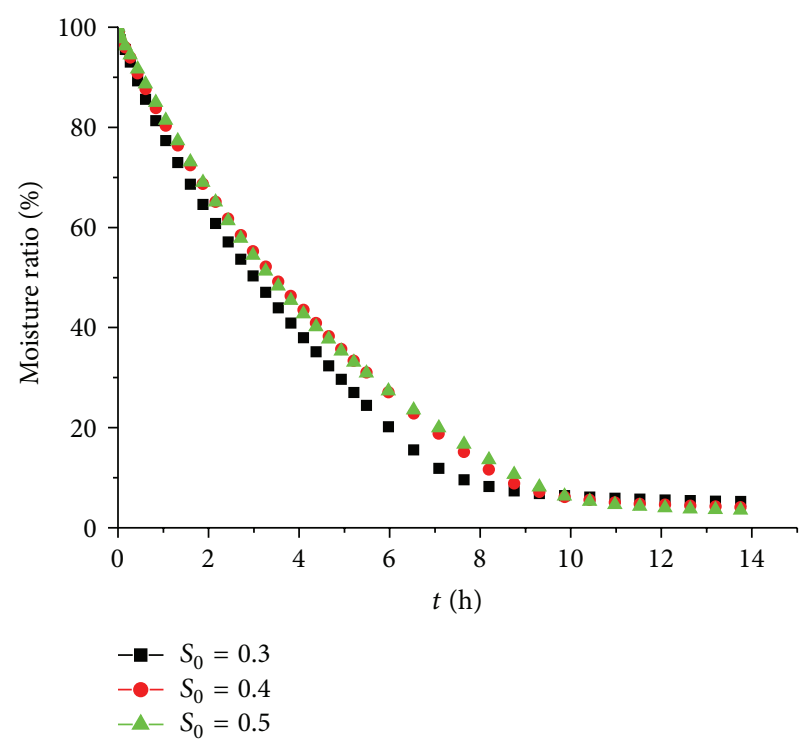

FIGURE 7: Moisture curves at different $S_{l 0}=0.5,0.4,0.3, k_{\text {cor }}=$ $10^{-15} \mathrm{~m}^{2}, k_{\text {in }}=10^{-13} \mathrm{~m}^{2}$.

8 , and 9 for $S_{l 0}=0.5,0.4,0.3$ with different cortex intrinsic permeability. To compare the results, moisture is represented by the moisture ratio $M / M_{0}$. The other parameters are $K_{r}=$ $1000, P_{v b}=1000 \mathrm{~Pa}$, and $T_{h}=323 \mathrm{~K}$. The drying time is about 10 hours, 6.5 hours, and 6 hours for $S_{l 0}=0.5,0.4,0.3$, respectively. In the same intrinsic permeability, the drying time is almost the same. The initial moisture has a less effect when initial moisture is 0.4 and 0.3 , especially cortex intrinsic permeability $k_{\text {cor }}=10^{-15} \mathrm{~m}^{2}$. The drying rate is little larger for $S_{l 0}=0.5$, and the drying rate is almost the same for $S_{l 0}=0.4,0.3$.

6.5. Effect of Heat Temperature. The effect of heat temperature on moisture is shown in Figures 10, 11, and 12 for the heat 


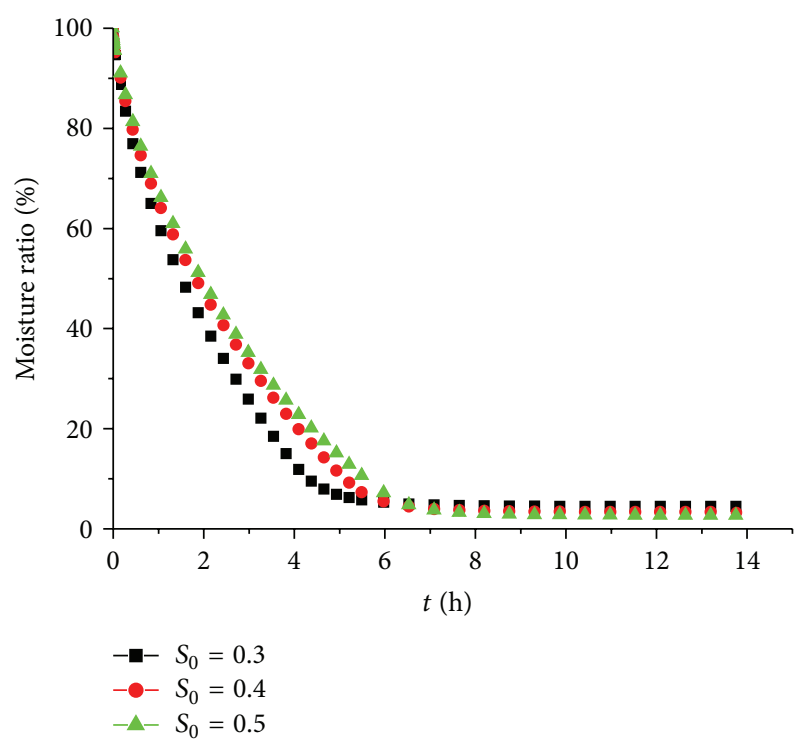

FIGURE 8: Moisture curves at different $S_{l 0}=0.5,0.4,0.3, k_{\text {cor }}=$ $10^{-14} \mathrm{~m}^{2}, k_{\text {in }}=10^{-13} \mathrm{~m}^{2}$.

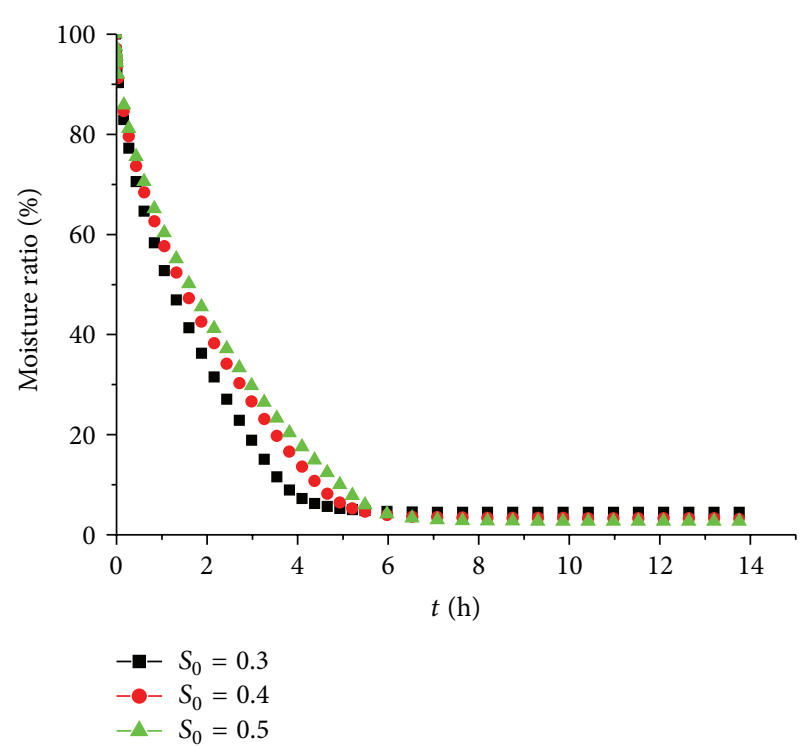

FIGURE 9: Moisture curves at different $S_{l 0}=0.5,0.4,0.3$, no cortex, $k_{\text {in }}=10^{-13} \mathrm{~m}^{2}$.

temperature $T_{h}=323,333$, and $343 \mathrm{~K}$. The other parameters are $S_{l 0}=0.5, K_{r}=1000$, and $P_{v}=1000 \mathrm{~Pa}$. The effect of heat temperature is obviously in all simulation. The drying time is more than 14 hours for $T_{h}=323 \mathrm{~K}, k_{\text {cor }}=10^{-15} \mathrm{~m}^{2}$, and $k_{\text {in }}=$ $10^{-13} \mathrm{~m}^{2}$. And it is about 10 hours and 8 hours for $T_{h}=333$, $343 \mathrm{~K}, k_{\mathrm{cor}}=10^{-15} \mathrm{~m}^{2}$, and $k_{\mathrm{in}}=10^{-13} \mathrm{~m}^{2}$. The drying time is more than 9 hours for $T_{h}=333 \mathrm{~K}, k_{\text {cor }}=10^{-15} \mathrm{~m}^{2}$, and $k_{\text {in }}=10^{-13} \mathrm{~m}^{2}$. It is about 7 hours and 6 hours for $T_{h}=333$, $343 \mathrm{~K}, k_{\mathrm{cor}}=10^{-15} \mathrm{~m}^{2}$, and $k_{\mathrm{in}}=10^{-13} \mathrm{~m}^{2}$. The drying time is more than 7 hours for $T_{h}=333 \mathrm{~K}, k_{\text {cor }}=10^{-15} \mathrm{~m}^{2}$, and $k_{\text {in }}=10^{-13} \mathrm{~m}^{2}$. It is about 6 hours and 5 hours for $T_{h}=333$, $343 \mathrm{~K}, k_{\text {cor }}=10^{-15} \mathrm{~m}^{2}$, and $k_{\text {in }}=10^{-13} \mathrm{~m}^{2}$.



FIGURE 10: Moisture curves at different $T_{h}=323,333,343 \mathrm{~K}, k_{\text {cor }}=$ $10^{-15} \mathrm{~m}^{2}, k_{\mathrm{in}}=10^{-13} \mathrm{~m}^{2}$.

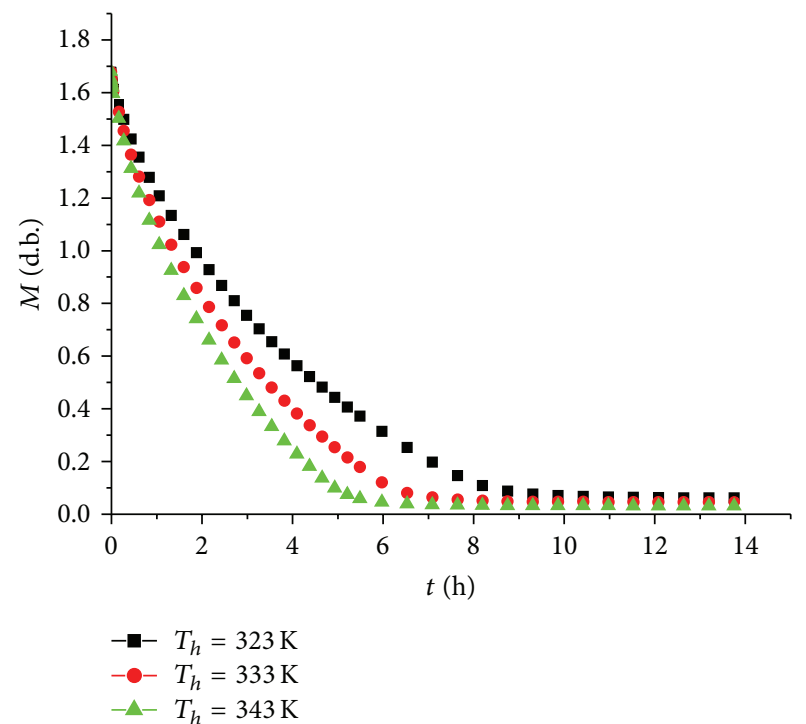

FIGURE 11: Moisture curves at different $T_{h}=323,333,343 \mathrm{~K}, k_{\text {cor }}=$ $10^{-14} \mathrm{~m}^{2}, k_{\text {in }}=10^{-13} \mathrm{~m}^{2}$.

\section{Conclusion}

A coupled model of porous medium vacuum drying with cortex effect based on the theory of heat and mass transfer was implemented in this paper. The drying rate is little higher at the drying initial stage for the same direction of heat and mass transfer, and then it is little lower. The drying time became evidently longer as the intrinsic permeability was reduced because the moisture movement velocity was lowered at the same pressure gradient. The difference is not so obvious as the $k_{\text {cor }}=10^{-14} \mathrm{~m}^{2}$, that is lower 10 -fold than inner medium. But when $k_{\text {cor }}=10^{-15} \mathrm{~m}^{2}$, the drying time is increased to $200 \%$ nearly. The vapor pressure has a greater effect on 


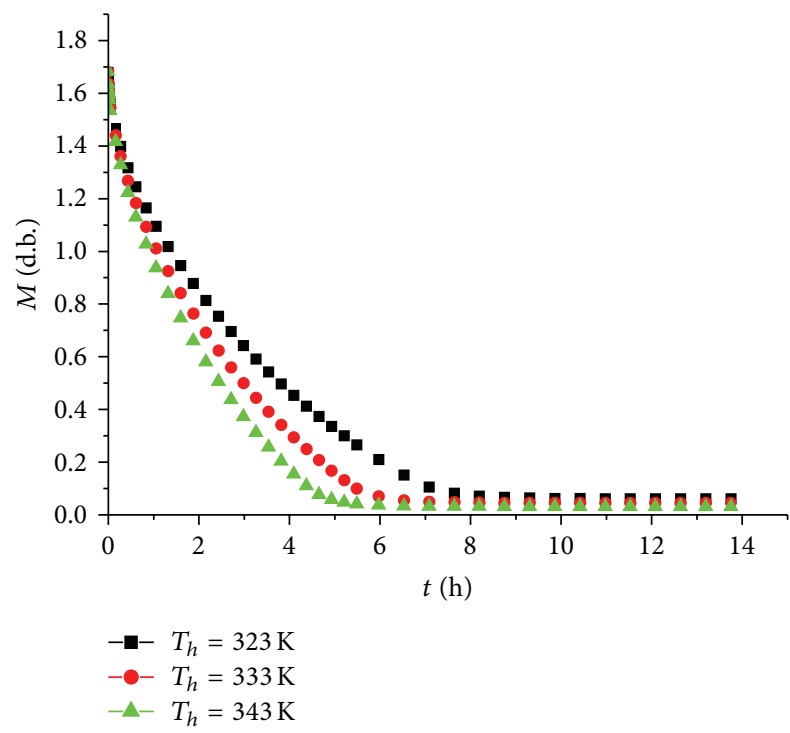

Figure 12: Moisture curves at different $T_{h}=323,333,343 \mathrm{~K}$, no cortex, $k_{\text {in }}=10^{-13} \mathrm{~m}^{2}$.

the drying process; a lower vapor pressure results in greater pressure degradation. But the pressure effect is lower by the reduction of the cortex intrinsic permeability. For initial moisture effect, in the same intrinsic permeability, the drying time is almost the same. The initial moisture is a less effect when initial moisture is 0.4 and 0.3 , especially cortex intrinsic permeability $k_{\text {cor }}=10^{-15} \mathrm{~m}^{2}$. The drying rate is little larger for $S_{l 0}=0.5$, and the drying rate is almost the same for $S_{l 0}=0.4,0.3$. The effect of heat temperature is obviously in all simulation.

\section{Nomenclature}

$\begin{array}{ll}B: & \text { Diagonal tensor } \\ D: & \text { Diffusivity }\left(\mathrm{m}^{2} \mathrm{~s}^{-1}\right) \\ D_{\text {eff }}: & \text { Diffusion tensor }\left(\mathrm{m}^{2} \mathrm{~s}^{-1}\right) \\ g: & \text { Gravity vector }\left(\mathrm{m} \mathrm{s}^{-2}\right) \\ h: & \text { Intrinsic averaged enthalpy }\left(\mathrm{Jkg}^{-1}\right) \\ I: & \text { Water phase rate }\left(\mathrm{kg} \mathrm{s}^{-1} \mathrm{~m}^{-3}\right) \\ k: & \text { Intrinsic permeability }\left(\mathrm{m}^{2}\right) \\ k_{r}: & \text { Relative permeability } \\ m: & \text { Mass }(\mathrm{kg}) \\ n: & \text { Outer unit normal to the product } \\ P: & \text { Pressure (Pa) } \\ P_{c}: & \text { Capillary pressure }(\mathrm{Pa}) \\ R: & \text { Universal Gas constant }\left(\mathrm{J} \mathrm{kmol}^{-1} \mathrm{~K}^{-1}\right) \\ S: & \text { Saturation } \\ t: & \text { Time (s) } \\ T: & \text { Temperature }(\mathrm{K}) \\ W: & \text { Moisture content (in dry basis). }\end{array}$

\section{Greek Letters}

$\Delta H$ : Latent of phase change $\left(\mathrm{Jkg}^{-1}\right)$

$\lambda_{\text {ef }}:$ Effective thermal conductivity tensor $\left(\mathrm{Wm}^{-1} \mathrm{k}^{-1}\right)$

\author{
$\mu:$ Viscosity $\left(\mathrm{kg} \mathrm{m}^{-1} \mathrm{~s}^{-1}\right)$ \\ $\rho$ : Density $\left(\mathrm{kg} \mathrm{m}^{-3}\right)$ \\ $\omega$ : Vapor fraction.
}

\author{
Subscripts \\ a: Dry air \\ g: Gas \\ l: $\quad$ Liquid \\ s: $\quad$ Solid \\ v: Vapor \\ sat: Vapor saturation \\ in: Inner medium \\ cor: Cortex.

\section{Mathematical Operators} \\ $\Delta:$ Gradient operator
$\nabla \cdot:$ Divergence operator.
}

\section{Acknowledgment}

This research was supported by the National Natural Science Foundation of China (Grant nos. 31000665 and nos. 51176027).

\section{References}

[1] C. H. Xu, Z. J. Zhang, S. W. Zhang, and X. He, "Probe into the structure of tower continuous vacuum dryer," in Proceedings of the 5th Asia-Pacific Drying Conference (ADC '07), pp. 1261-1267, August 2007.

[2] Z. J. Zhang, C. H. Xu, S. W. Zhang, and X. He, "The study of corn low temperature continuous tower type vacuum dryer," in Proceedings of the 5th Asia-Pacific Drying Conference (ADC '07), pp. 330-337, August 2007.

[3] Z. Zhang, C. Xu, S. Zhang, and L. Zhao, "Computer simulation of flow field in tower continuous vacuum dryer," in Proceedings of the International Conference on Computer Science and Information Technology (ICCSIT '08), pp. 534-538, September 2008.

[4] I. Yasuaki and A. P. S. Selvadurai, Transport Phenomena in Porous Media, Aspects of Micro/Macro Behaviour, Springer, 2012.

[5] A. K. Haghi, "Transport phenomena in porous media: a review," Theoretical Foundations of Chemical Engineering, vol. 40, no. 1, pp. 14-26, 2006.

[6] S. J. Kowalski, Drying of Porous Materials, Springer, 2007.

[7] B. Jacob and Y. Bachmat, Introduction to Modeling of Transport Phenomena in Porous Media, Springer, 1990.

[8] A. Erriguible, P. Bernada, F. Couture, and M. A. Roques, "Simulation of vacuum drying by coupling models," Chemical Engineering and Processing, vol. 46, no. 12, pp. 1274-1285, 2007.

[9] A. Erriguible, P. Bernada, F. Couture, and M. A. Roques, "Modeling of heat and mass transfer at the boundary between a porous medium and its surroundings," Drying Technology, vol. 23, no. 3, pp. 455-472, 2005.

[10] K. Murugesan, H. N. Suresh, K. N. Seetharamu, P. A. Aswatha Narayana, and T. Sundararajan, "A theoretical model of brick drying as a conjugate problem," International Journal of Heat and Mass Transfer, vol. 44, no. 21, pp. 4075-4086, 2001. 
[11] P. Perré and I. W. Turner, "A dual-scale model for describing drier and porous medium interactions," AIChE Journal, vol. 52, no. 9, pp. 3109-3117, 2006.

[12] S. S. Torres, W. Jomaa, J.-R. Puiggali, and S. Avramidis, "Multiphysics modeling of vacuum drying of wood," Applied Mathematical Modelling, vol. 35, no. 10, pp. 5006-5016, 2011.

[13] S. S. Torres, J. R. Ramírez, and L. Méndez-Lagunas, "Modeling plain vacuum drying by considering a dynamic capillary pressure," Chemical and Biochemical Engineering Quarterly, vol. 25, no. 3, pp. 327-334, 2011.

[14] A. Warning, A. Dhall, D. Mitrea, and A. K. Datta, "Porous media based model for deep-fat vacuum frying potato chips," Journal of Food Engineering, vol. 110, no. 3, pp. 428-440, 2012.

[15] A. Halder, A. Dhall, and A. K. Datta, "An improved, easily implementable, porous media based model for deep-fat frying. Part I: model development and input parameters," Food and Bioproducts Processing, vol. 85, no. 3 C, pp. 209-219, 2007.

[16] A. Halder, A. Dhall, and A. K. Datta, "An improved, easily implementable, porous media based model for deep-fat frying. Part II: results, validation and sensitivity analysis," Food and Bioproducts Processing, vol. 85, no. 3, pp. 220-230, 2007.

[17] Z. Zhang and N. Kong, "Nonequilibrium thermal dynamic modeling of porous medium vacuum drying process," Mathematical Problems in Engineering, vol. 2012, Article ID 347598, 22 pages, 2012. 


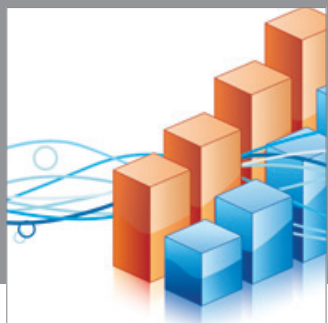

Advances in

Operations Research

mansans

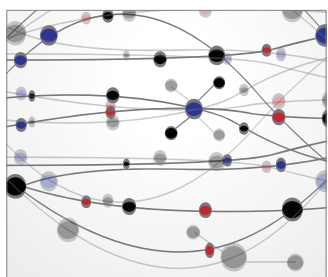

The Scientific World Journal
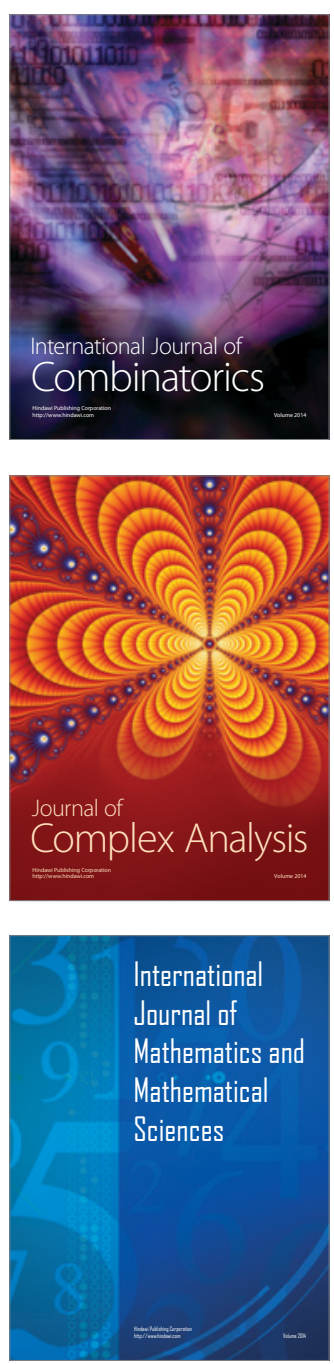
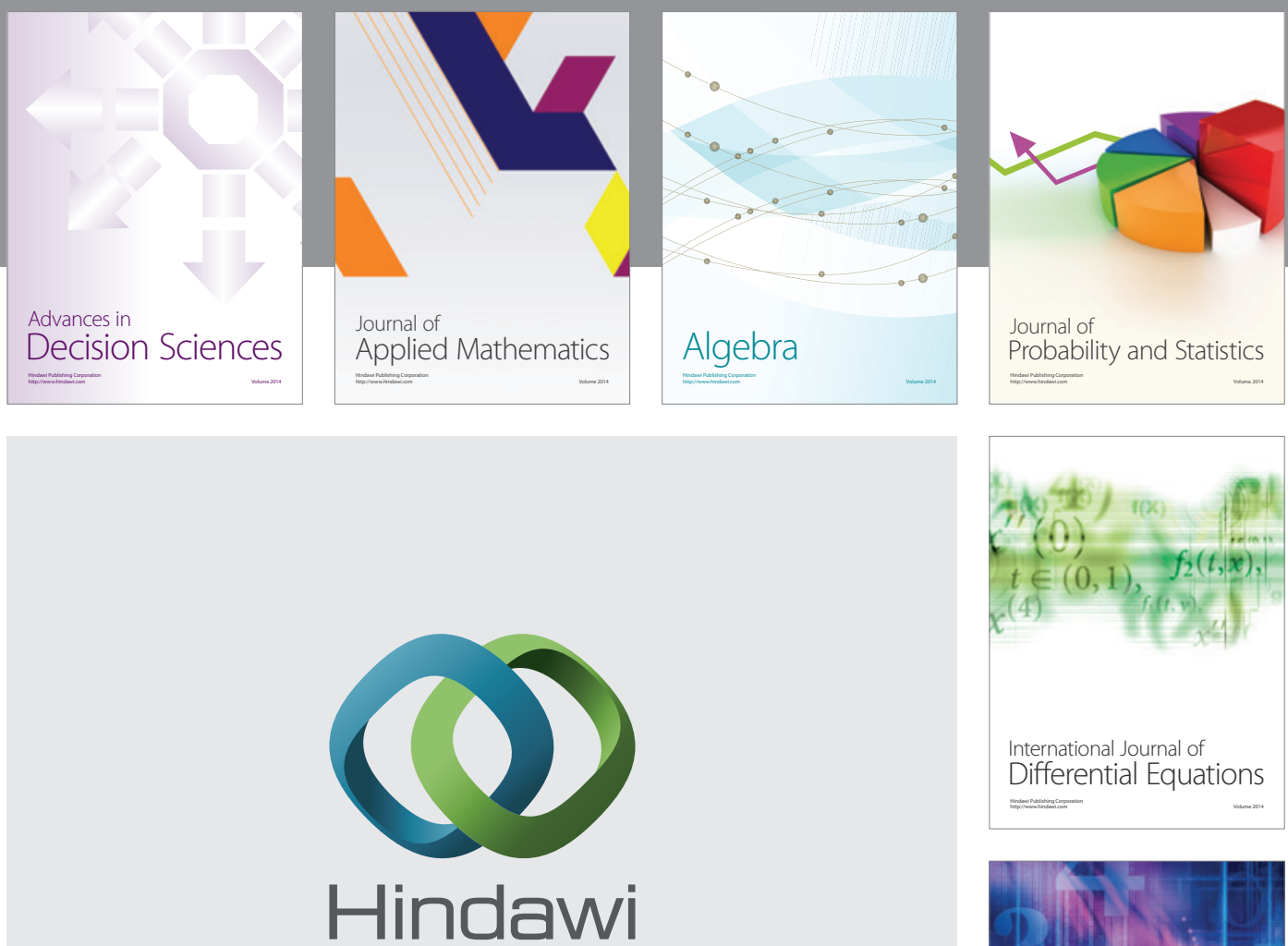

Submit your manuscripts at http://www.hindawi.com
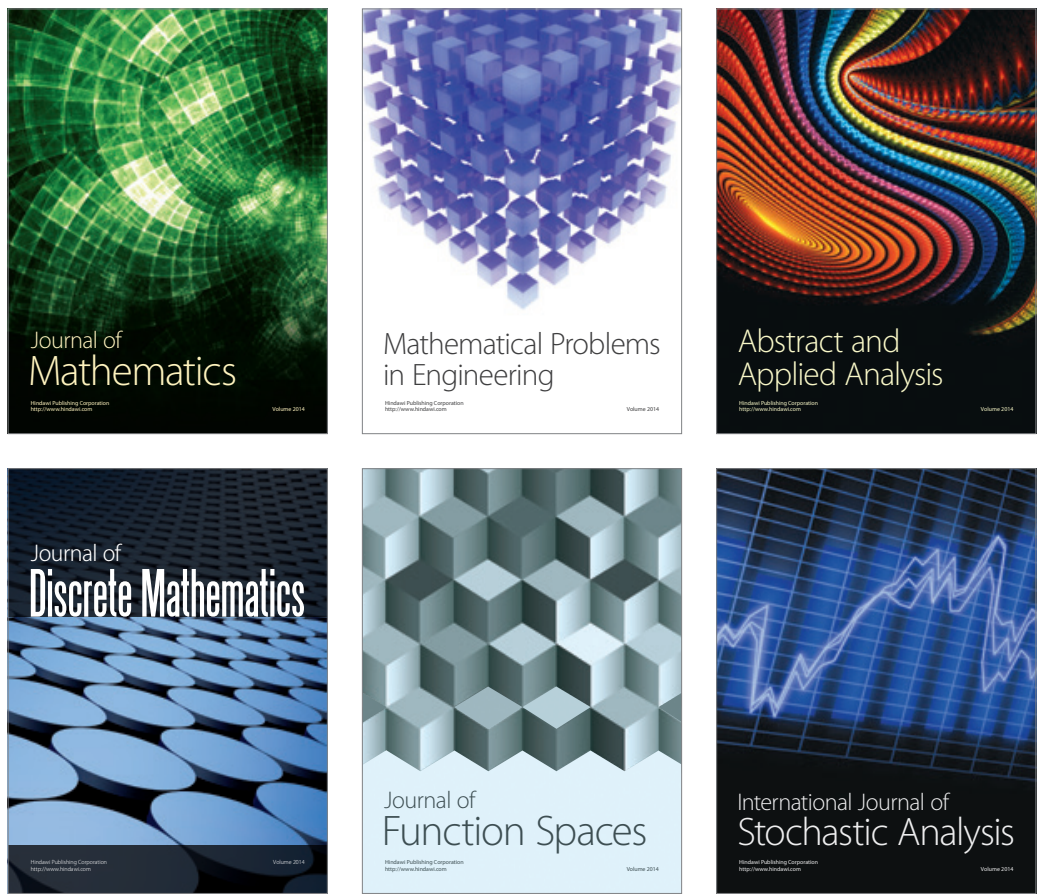

Journal of

Function Spaces

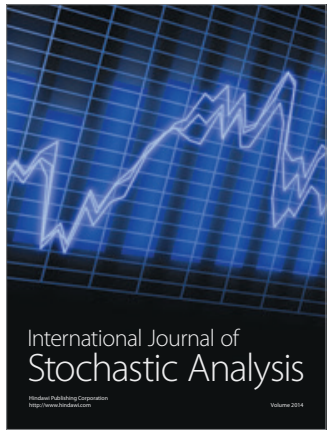


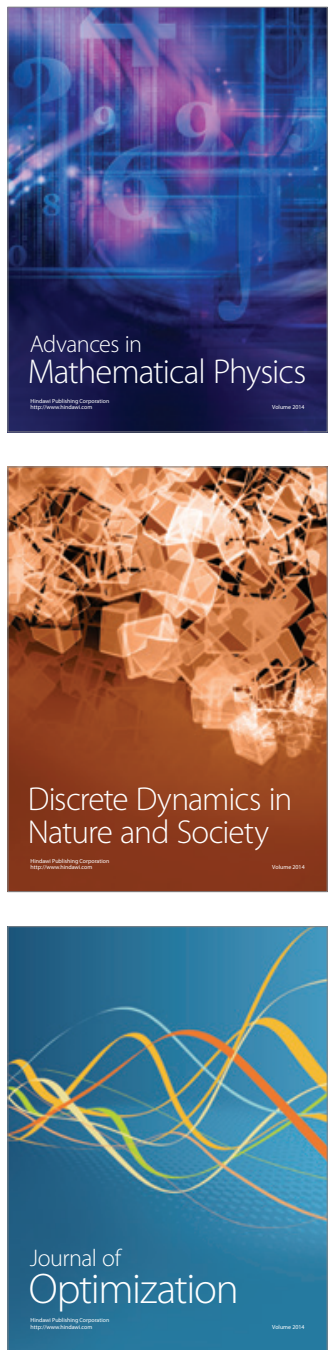